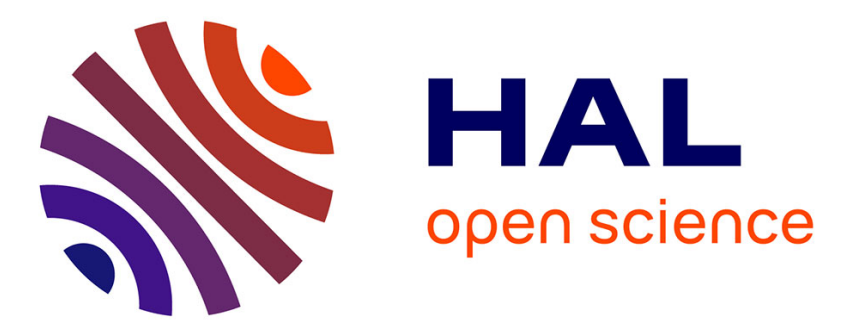

\title{
High Cycle Fatigue Strength of Punched Thin Fe-Si Steel Sheets
}

Helmi Dehmani, Charles Brugger, Thierry Palin-Luc, Charles Mareau, Samuel Koechlin

\section{- To cite this version:}

Helmi Dehmani, Charles Brugger, Thierry Palin-Luc, Charles Mareau, Samuel Koechlin. High Cycle Fatigue Strength of Punched Thin Fe-Si Steel Sheets. Materials Performance and Characterization, 2016, 5 (3), pp.1-15. 10.1520/MPC20150063 . hal-01375905

\section{HAL Id: hal-01375905 https://hal.science/hal-01375905}

Submitted on 3 Oct 2016

HAL is a multi-disciplinary open access archive for the deposit and dissemination of scientific research documents, whether they are published or not. The documents may come from teaching and research institutions in France or abroad, or from public or private research centers.
L'archive ouverte pluridisciplinaire HAL, est destinée au dépôt et à la diffusion de documents scientifiques de niveau recherche, publiés ou non, émanant des établissements d'enseignement et de recherche français ou étrangers, des laboratoires publics ou privés. 
'Emerson-Leroy Somer, Blvd. Marcellin Leroy, Angoulême, France.

${ }^{2}$ Arts et Métiers ParisTech, I2M, CNRS, Esplanade des Arts et Métiers, Talence, France (Corresponding authors), e-mail: helmi.dehmani@ensam.eu; charles.brugger@ensam.eu; thierry.palin-luc@ensam.eu

${ }^{3}$ Arts et Métiers ParisTech, LAMPA, Blvd. du Ronceray, Angers, France,

(Corresponding author)

e-mail: charles.mareau@ensam.eu
Helmi Dehmani, ${ }^{1,2,3}$ Charles Brugger, ${ }^{2}$ Thierry Palin-Luc, ${ }^{2}$

Charles Mareau, ${ }^{3}$ and Samuel Koechlin ${ }^{1}$

\section{High Cycle Fatigue Strength of Punched Thin Fe-Si Steel Sheets}

\section{Reference}

Dehmani, H., Brugger, C., Palin-Luc, T., Mareau, C., and Koechlin, S., "High Cycle Fatigue Strength of Punched Thin Fe-Si Steel Sheets," Materials Performance and Characterization, Vol. 5, No. 3, 2016, pp. 1-14, doi:10.1520/MPC20150063. ISSN 2165-3992

\section{ABSTRACT}

Some parts of electrical machines are built from stacks of thin steel sheets, for which the coarse grain microstructure allows for minimizing magnetic losses. The fabrication process of these parts usually involves punching operations that generate important defects on the edges. Since these alterations may result in a degradation of the fatigue strength, this study aims at elaborating on a fatigue design strategy for such punched parts. To reach this objective, high cycle fatigue tests are performed on different specimens with either punched or polished edges. The results show a significant decrease of the fatigue strength for punched specimens. Scanning electron microscope observations of specimen facture surfaces reveal that defects on punched edges are at the origin of the fatigue cracks. The influence of temperature is also investigated. Fatigue tests are performed at ambient temperature $\left(20^{\circ} \mathrm{C}\right)$ and at $180^{\circ} \mathrm{C}$. According to the experimental results, no significant influence on the median fatigue strength is observed. Since crack initiation always occur on the edges, additional investigations are performed to characterize how edges are altered by punching operations. Residual stresses are determined on punched edges using x-ray diffraction techniques. As a consequence of punching, important tensile residual stresses exist along the loading direction. In association with the stress concentration caused by geometrical defects, residual stresses promote crack initiation and fast crack propagation. For a better understanding of crack initiation, edge geometries are scanned with a 
3D optical profilometer, allowing us to identify the critical defect. It is found that the typical defect size is comparable to the grain size.

\section{Keywords}

Fe-Si steel sheet, HCF fatigue, punching effect, temperature effect, residual stress, defect

\section{Introduction}

The development of high speed electric motors is submitted to stringent conditions: high efficiency levels over a wide speed range, weight reduction to optimize the motor volume, excellent reliability, and low production costs. In order to satisfy these conditions, new electrical steel grades, with improved magnetic properties, are used to build these motors. For these steel grades, the iron losses are reduced by adjusting the chemical composition (mostly the Si content), decreasing the thickness below $0.5 \mathrm{~mm}$ and increasing the grain size. Rotors of electrical machines, which include stacks of such thin sheets, are mass-produced using a punching process. Since rotors are subjected to cyclic loadings, safely designing electrical machines against fatigue failure requires the understanding of the influence of punching operations on the fatigue behavior of Fe-Si thin sheets. As shown in different studies [1-5], important geometrical defects resulting from punching operations are observed on edges. Such defects, because they can be considered as potential fatigue crack initiation sites, are partly responsible for a degradation of the fatigue strength. Also, in addition to geometrical defects, the punching process locally induces both hardening and residual stresses on the edge $[3,4,6-8]$. These phenomena are observed on either thick $(15 \mathrm{~mm})$ or thin $(0.23 \mathrm{~mm})$ sheets and contribute to an important degradation of the fatigue resistance $[1,2]$.

The main objective of this work is to study the effect of the punching process on the high cycle fatigue resistance of thin sheets. More specifically, the roles of geometrical defects, hardening and residual stresses induced by this process are studied. Micro-hardness measurements are performed to evaluate the important hardness gradient near punched edges. X-ray diffraction techniques are used to analyze the residual stresses resulting from punching operations. The punched edges are investigated using microscopy and 3D surface topography in order to identify the critical defect and to obtain its geometry. Finally, the capability of the Murakami and Crossland fatigue criteria to account for the influence of the alterations caused by punching operations on the high cycle fatigue behavior of thin electrical steel sheets is evaluated.

\section{Material and Testing Conditions}

The investigated material is a non-oriented fully-processed sheet of Fe-Si electrical steel graded as M330-35A according to the EN10106 standard. It is delivered in the form of rolled sheets with a $0.35 \mathrm{~mm}$ nominal thickness. Its chemical composition is given (in mass percentage range) as follows: [ $2 \%-3.5 \%$ ] of $\mathrm{Si}$, [0.2 \% - $0.6 \%$ ] of $\mathrm{Mn},[0.4 \%-1.2 \%$ ] of $\mathrm{Al}$, and [95 \% - $98 \%$ ] of Fe. Metallographic observations 
FIG. 1 Pole figures obtained by EBSD analysis on the studied material.
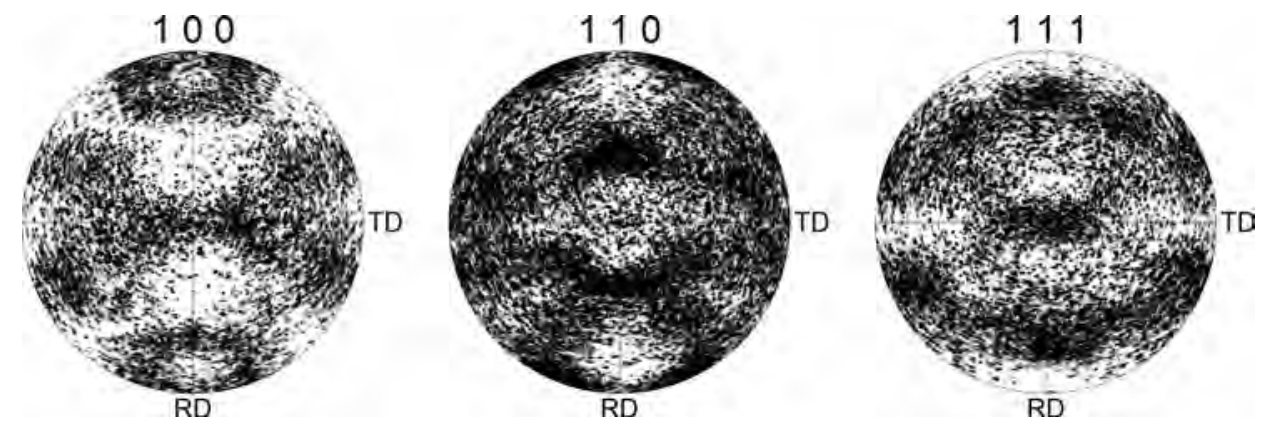

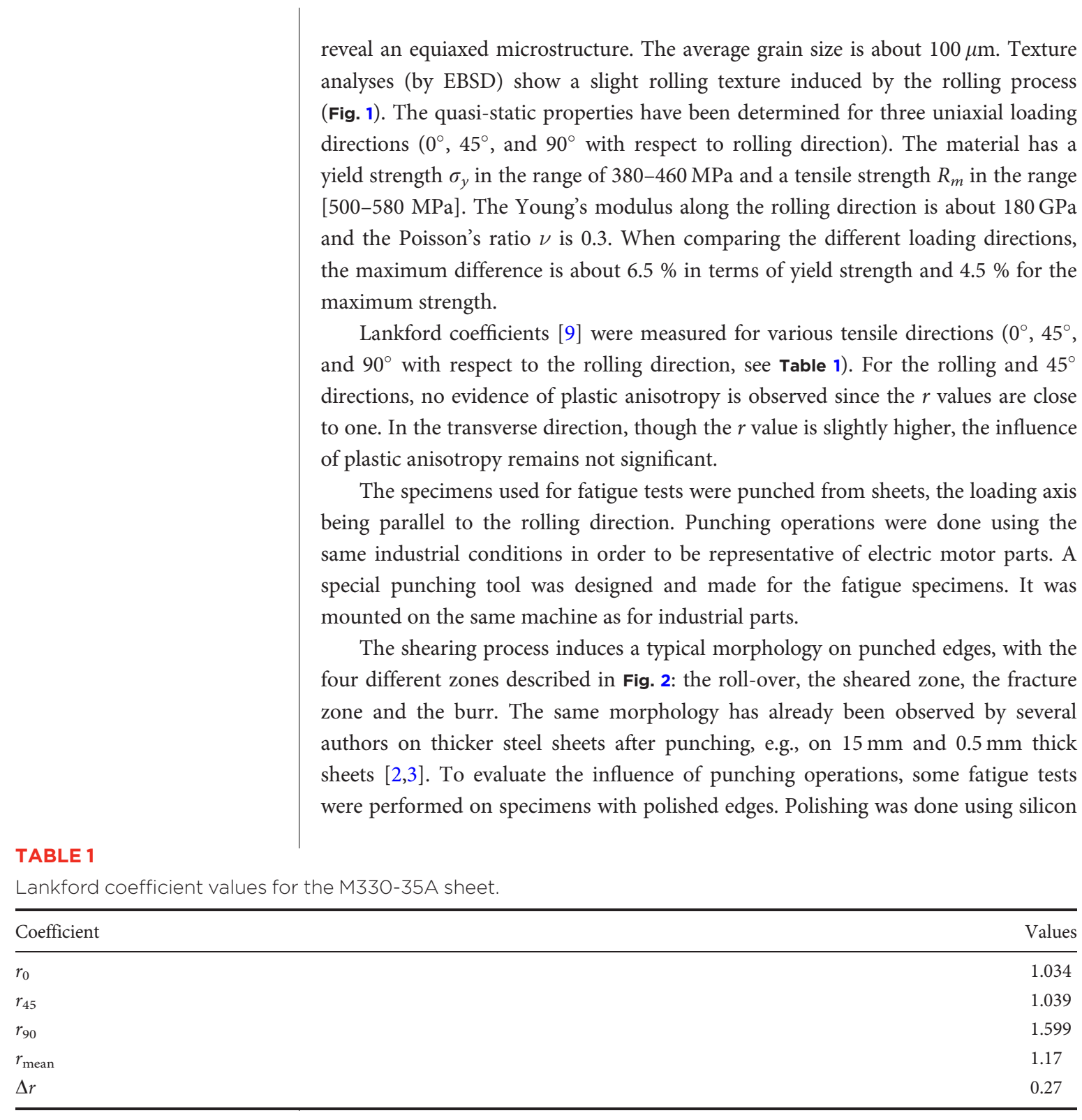


FIG. 2 Different zones observed on the punched edges.
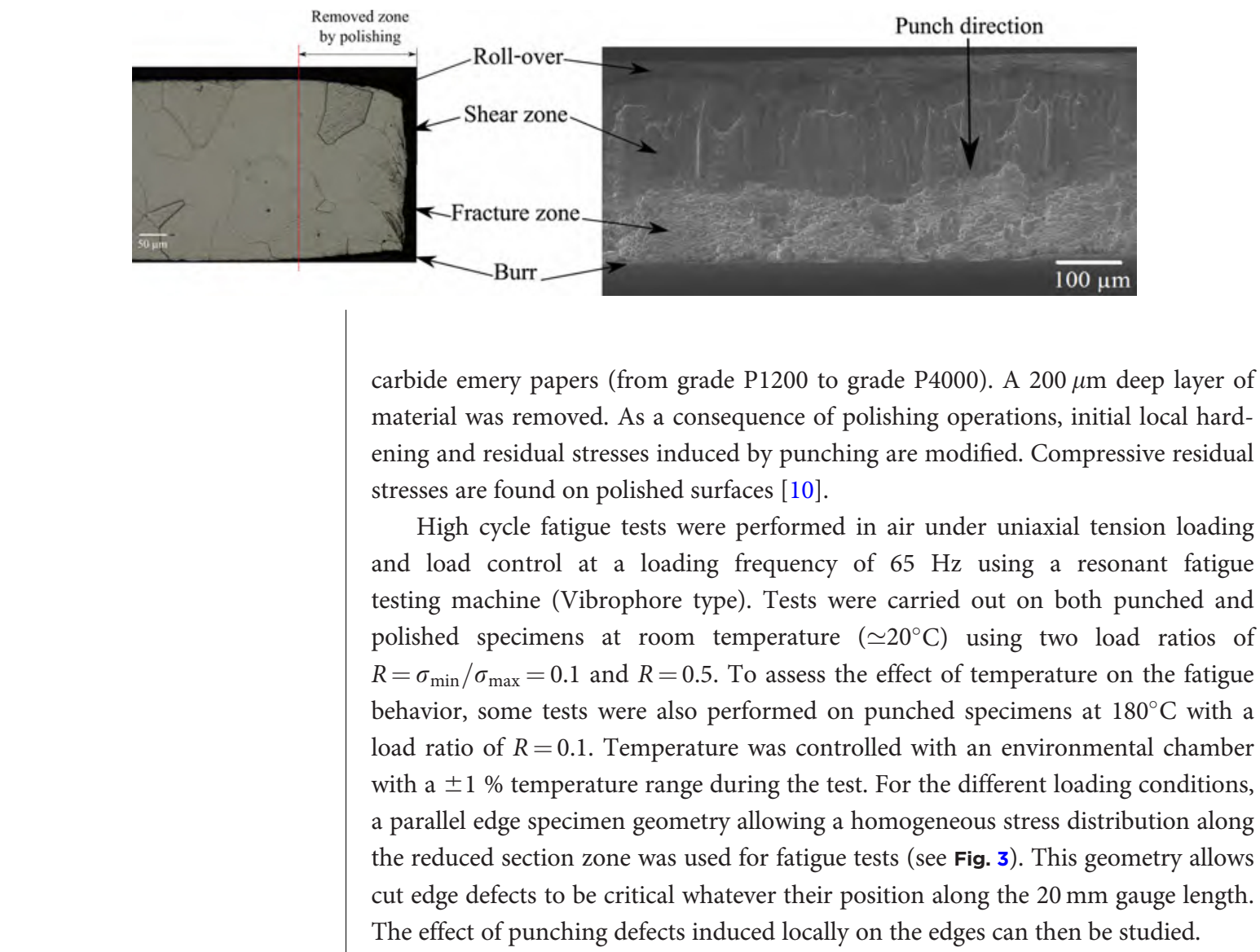

\section{Results and Discussion}

\section{FATIGUE TEST RESULTS}

\section{Comparison Between Punched and Polished Specimens}

The $S$ - $N$ curves relative to punched and polished specimens are presented in Fig. 4. For confidentiality reasons, stress amplitudes are normalized by the median fatigue strength at $5 \times 10^{6}$ cycles for punched specimens. For $R=0.1$, when compared to

FIG. 3

Specimen geometry used for the fatigue tests (thickness: $0.35 \mathrm{~mm}$ ).

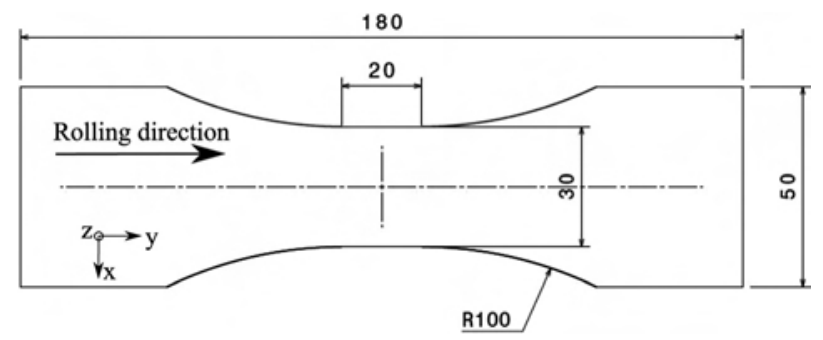


FIG. 4 S-N curves for punched and polished specimens (a) $R=0.1$ and (b) $R=0.5$ (Stromeyer fit [11]).
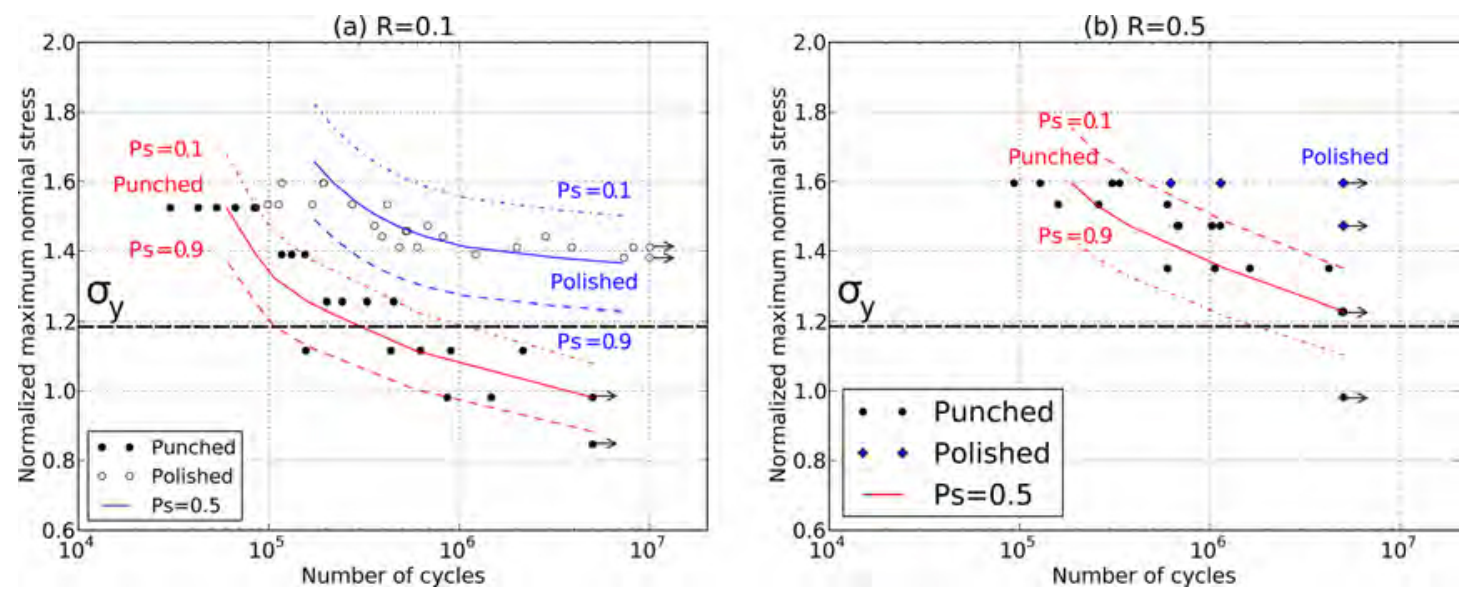

polished specimens, the median fatigue strength at $5 \times 10^{6}$ cycles shows a drop of about $30 \%$ in the case of punched specimens [Fig. 4(a)]. As shown later, at such low stress levels, the defects introduced by the cutting process cause fatigue crack initiation. At higher stress levels, the difference between punched and polished specimens reduces, as fatigue crack initiation is more and more governed by macroscopic plasticity. Results relative to $R=0.5$ in Fig. $\mathbf{4 ( b )}$ show that the fatigue strength drop is reduced to approximately $17 \%$ only with regard to polished specimens. Indeed, since the maximum stresses are higher for $R=0.5$, the role of macroscopic plasticity is more important than for $R=0.1$.

\section{Influence of the Temperature}

Fig. 5 shows the $S-N$ curves for the punched specimens tested at room temperature and at $180^{\circ} \mathrm{C}$ under $R=0.1$. No difference of the median fatigue strength at $5 \times 10^{6}$ cycles was observed for the two tested temperatures $\left(20^{\circ} \mathrm{C}\right.$ and $\left.180^{\circ} \mathrm{C}\right)$ conditions.

FIG. 5

S-N curves for punched and polished specimens tested at room temperature and at $180^{\circ} \mathrm{C}$ (Stromeyer fit [11]).

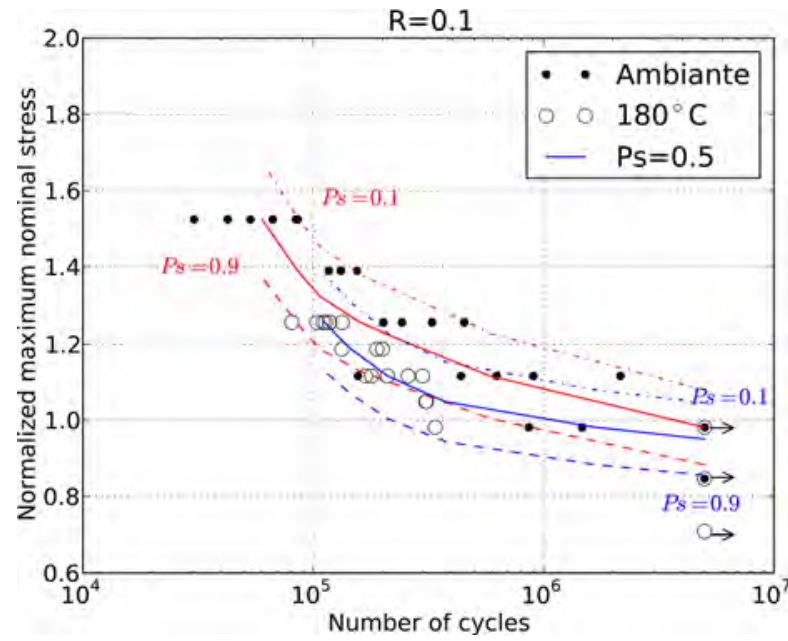


FIG. 6 Crack length measurements during a fatigue test $\left(N_{f}=187595\right.$ cycles $)$.

(a)

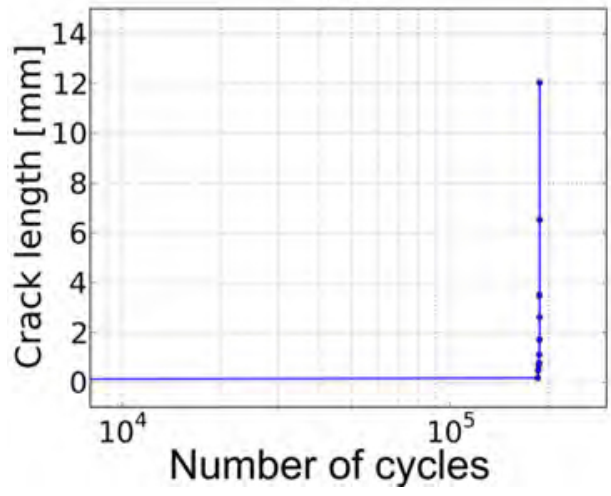

(b)

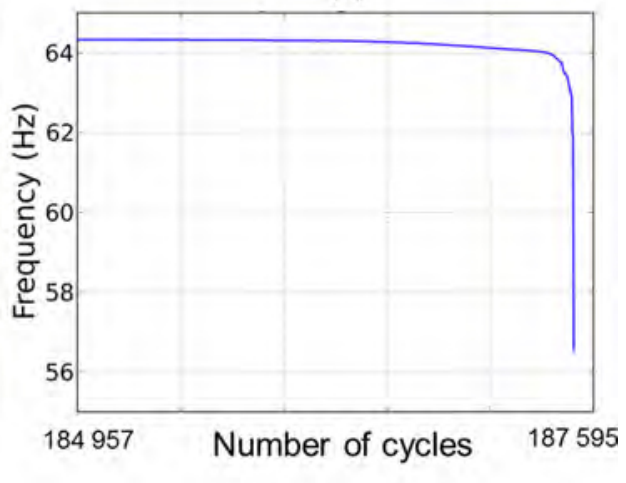

However, at higher stress levels, when macroscopic plasticity governs crack initiation, the temperature effect is visible. For a given stress level, specimens tested at $180^{\circ} \mathrm{C}$ fail sooner than specimens tested at ambient temperature. Scanning electron microscope (SEM) observations of the fracture surfaces relative to specimens tested at $180^{\circ} \mathrm{C}$ show the same crack initiation mechanisms as for room temperature.

\section{Fatigue Crack Propagation}

Some specimens were observed with a high resolution CCD camera to record both the crack initiation and propagation. For specimens tested at room temperature under $R=0.1$, the smallest detected crack is $0.174 \mathrm{~mm}$ long. During fatigue tests, a fast crack propagation was observed. Figs. $\mathbf{6 ( a )}$ and $\mathbf{6 ( b )}$ show that the number of cycles for propagation represents only about $1 \%$ of the total number of cycles to failure. As a consequence, $S-N$ curves are given for the initiation of a technical crack since crack initiation dominates the fatigue life in our testing conditions.

\section{FRACTOGRAPHIC OBSERVATIONS}

In order to investigate the causes of the fatigue strength drop and to identify the crack initiation mechanisms, the fracture surfaces have been observed after failure for both punched and polished specimens. For punched specimens, SEM observations show that cracks always initiate on edges, and in almost all cases, on a punching defect located in the fracture zone, as illustrated by Figs. $\mathbf{7 ( a )}$ and $\mathbf{6 ( b )}$. For polished specimens, short crack propagation seems more crystallographic, as shown in Fig. $\mathbf{7 ( c )}$. No influence of the temperature on the fatigue crack initiation mechanisms was observed. Three different zones are visible on the fracture surfaces of punched and polished specimens: (i) an initiation zone (with a length between 0.5 and $1.5 \mathrm{~mm}$ ) where the river lines converge to a punching defect located on the edge. Transgranular crack propagation is observed in this zone. (ii) A crystallographic zone which corresponds to the stable fatigue crack propagation. The mode change can be observed on Fig. $\mathbf{7}$ (d). (iii) Finally, a ductile zone relative to the final specimen breaking. The transition between the two modes is also observed by Schayes et al. [12]. According to these authors, the crack propagation mode depends 
FIG. 7 SEM observations of the fracture surface of punched specimen (a), (d) $R=0.1,(b) R=0.5$, and polished edge specimen (c) $\mathrm{R}=0.1$.
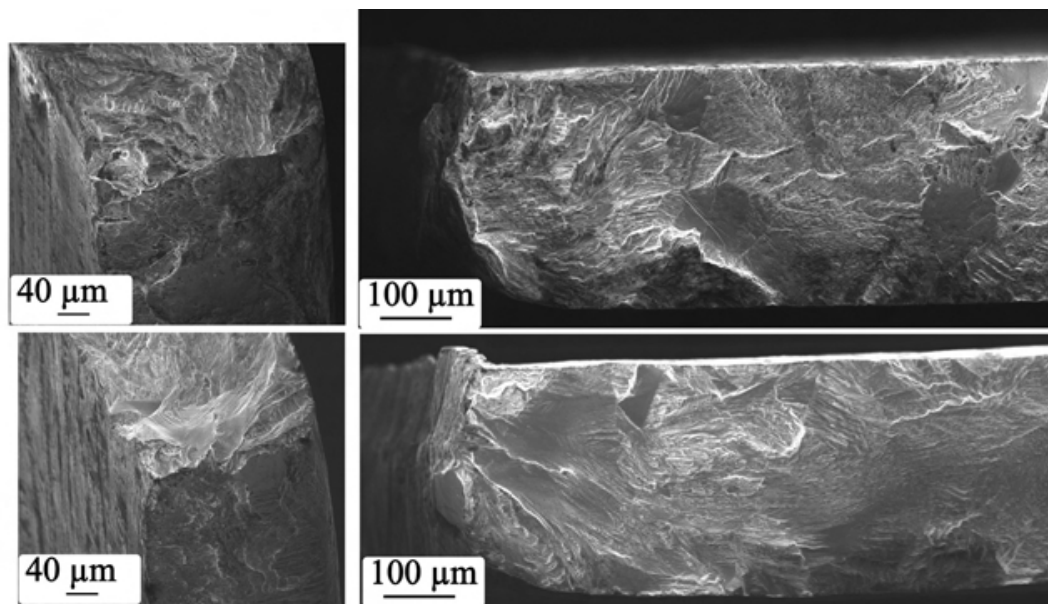

(a)
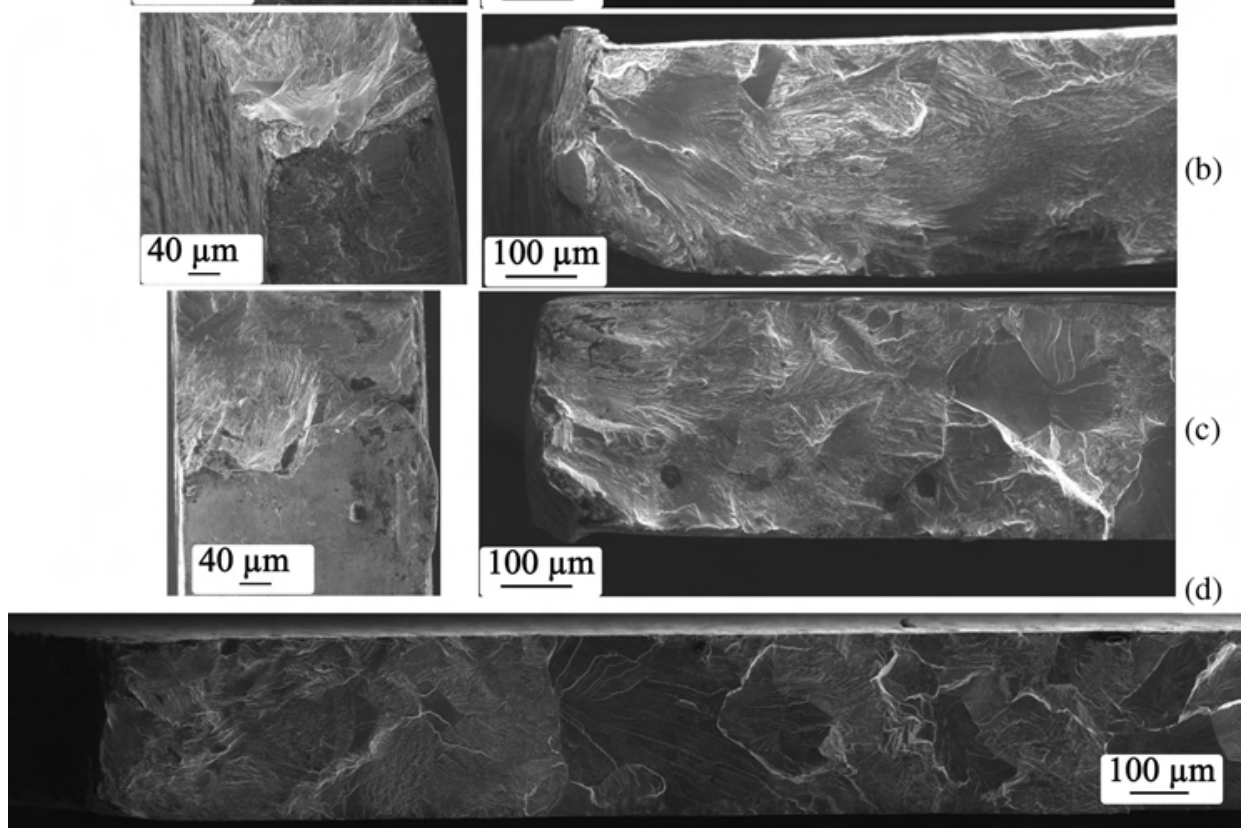

on the applied strain amplitude. It changes from transgranular to intergranular when the strain amplitude exceeds $0.7 \%$. Since in our case the tests are conducted under load control, it is difficult to compare with these results.

Fracture surface observations reveal an important role of the punching defects on fatigue crack initiation. However, hardening and residual stresses have an important contribution on the fatigue strength drop. The effect of hardening and residual stresses in addition to punching defect will be investigated in the following.

\section{MICRO-HARDNESS AND RESIDUAL STRESSES}

Micro-hardness measurements (HV 0.1) were carried out in the middle of the sheet thickness, starting from the punched edge. The first indentation was $50 \mu \mathrm{m}$ far from the punched edge, and then indentations were spaced with $75 \mu \mathrm{m}$ in order to avoid any measurement interferences. The results show that microhardness increases when approaching the punched edge (Fig. 8). From a mean value of $233 \mathrm{HV}$, it rises up to a value of $317 \mathrm{HV}$, at a distance of $50 \mu \mathrm{m}$ from 
FIG. 8

Micro-hardness measurements starting from the punched edge.

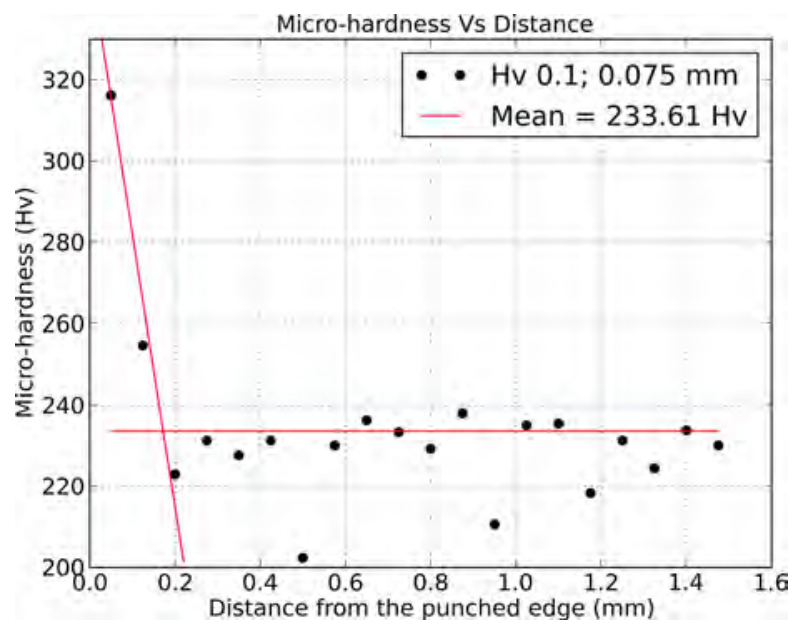

the punched edge. It can be concluded that the depth of the zone affected by punching is about $200 \mu \mathrm{m}$.

Residual normal stresses $\sigma_{y y}$ induced by the punching process on the specimen edges were analyzed by using $\mathrm{x}$-ray diffraction techniques (see Fig. $\mathbf{3}$ for the coordinate system). When focusing on the edge of a single sheet, the number of grains in the irradiated volume is too small to reliably determine the residual stress state. This is due to the small sheet thickness and to the coarse grain microstructure. Analyses have then been performed on a stack of ten sheets. Each stress value is estimated on an irradiated zone which approximately corresponds to a $2 \mathrm{~mm}$ diameter disk. Residual stress values have been determined first on the punched edge surface, then on surfaces obtained after successive layer removal using electrochemical polishing technique, up to a $180 \mu \mathrm{m}$ depth. The residual stress $\sigma_{y y}$ corresponds to the normal component of the residual stress tensor parallel to the rolling direction. Fig. 9
FIG. 9

Longitudinal residual stress $\sigma_{y y}$ on the edge along depth.

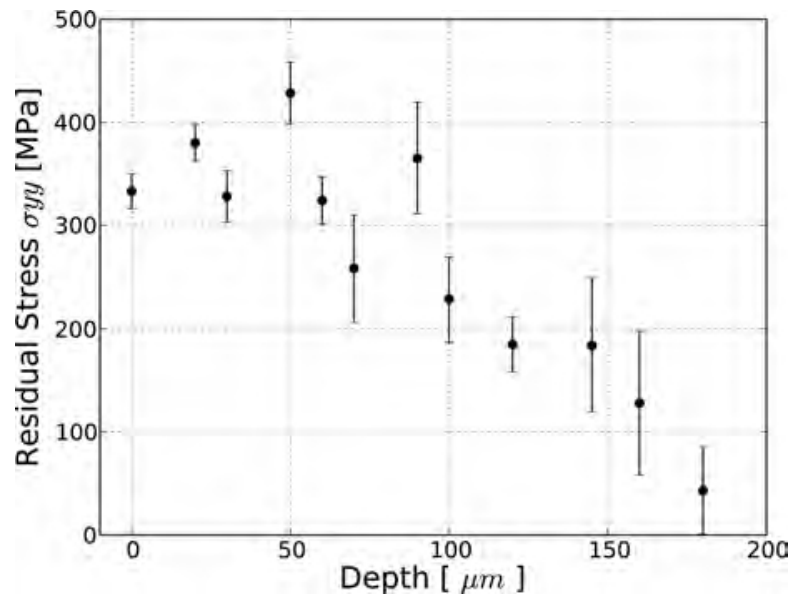


FIG. 10 Different types of defect in the punched edge.
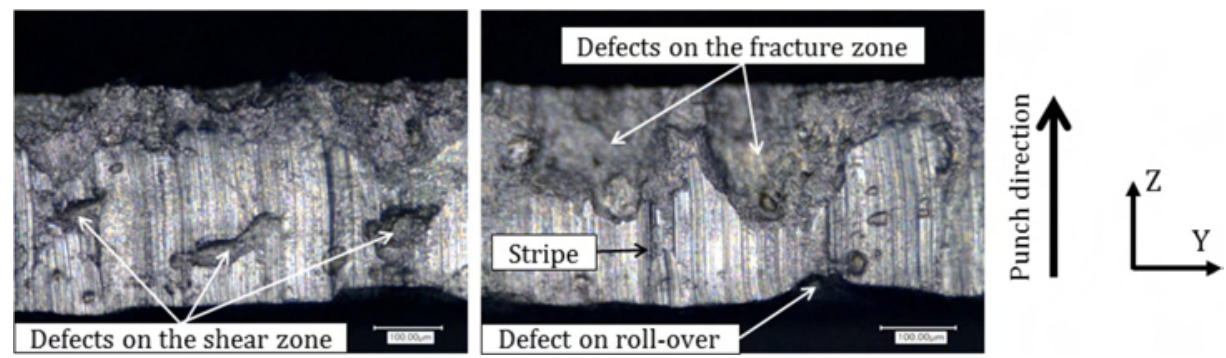

presents the evolution of $\sigma_{y y}$ along the depth (X-axis). Very high tensile residual stress values are found on the edge.

The profile presents a maximum located at $50 \mu \mathrm{m}$ below the surface, the longitudinal residual stress then decreases when increasing depth. The affected zone is about $200 \mu \mathrm{m}$ deep. This depth value is consistent with the depth of the hardened layer determined by micro-hardness measurements (Fig. 8). In depth, XRD measurement uncertainties related to the large grain size increase up to being the same magnitude as the stress values.

\section{MICROSCOPIC OBSERVATIONS AND 3D SURFACE PROFILOMETRY OF THE EDGES: CRITICAL DEFECTS IDENTIFICATION}

To better understand the fatigue strength drop in the case of punched specimens, punched edges were analyzed through both microscopic observations and three dimensional surface topography. Four types of defects were identified from microscopic observations (Fig. 10): (i) vertical stripes from the top to the bottom of the edge, (ii) depressions in the top surface (roll-over defects), (iii) defects in the sheared zone, and (iv) defects in the fracture zone, with typical dimensions close to those of a grain.

The three dimensional surface topography zone is $30 \mathrm{~mm}$ long, and then contains the entire reduced section and a part of the specimen radius. The resolution used for edge surface sampling is $0.89 \mu \mathrm{m}$ along $Y$ and $Z$ axes, and the measurement

FIG. 11 Identification of the fatigue crack initiation defect (a) surface profilometry and (b) optical pictures of the broken specimen after the fatigue test.

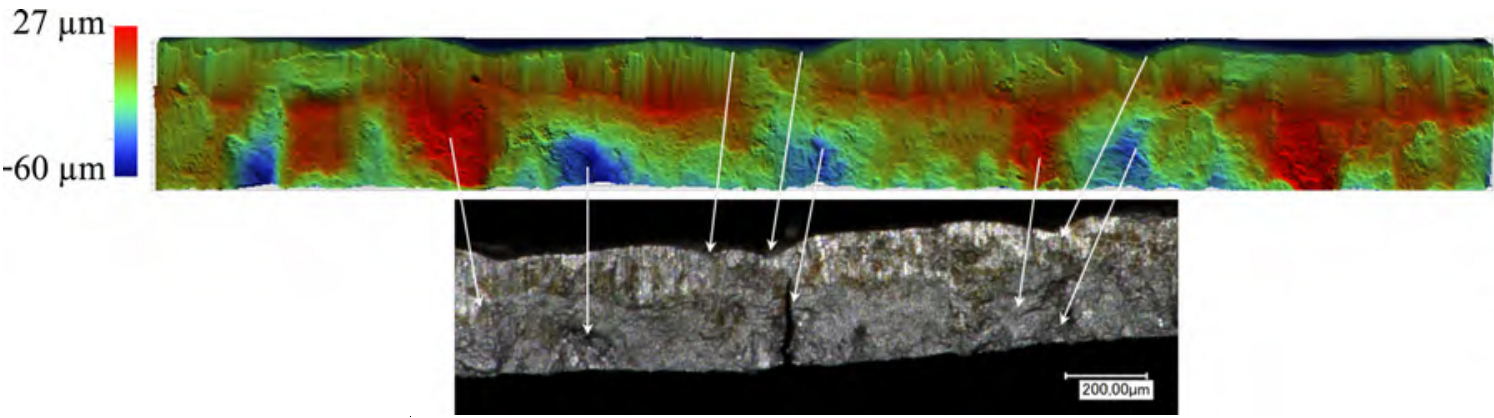


resolution along the $X$ axis was $10 \mathrm{~nm}$ (see coordinate system Fig. 3). Results show an irregular edge surface with the four types of defects identified by microscopic observations in the different zones of the edge (roll over, shear, and fracture), as illustrated in Fig. 11(a). After specimen failure, the defect on which fatigue crack initiation occurred is identified by comparing scans performed before testing and optical microscopy observations of the same specimen after fatigue failure (Fig. 11). These results confirm the SEM observations relative to punched specimens: critical defects are located in the fracture zone.

Optical profilometry scans provide the 3D geometry of defects. Typical defects are about $40 \mu \mathrm{m}$ deep and $150 \mu \mathrm{m}$ high. The intersection surface between typical defects and the $(X, Z)$ plane (perpendicular to the tension axis, i.e., depth of defect) was measured to quantify the Murakami's parameter $(\sqrt{\text { area }})$.

\section{Fatigue Strength Criterion}

Based on the 3D surface profilometry results, Murakami fatigue criterion was used to plot the Kitagawa diagram of the studied electrical steel. The square root area parameter $(\sqrt{\text { area }})$ is defined by Murakami [13] as the flaw size. It was obtained from scan data and its value is comprised between 50 and $80 \mu \mathrm{m}$. The relation between the fatigue limit in term of stress amplitude and the flaw size of typical defects is given by $\mathrm{Eq}(1)$

$$
\sigma_{D}=\frac{A(H V+120)}{\sqrt{\text { area }}^{1 / 6}} \times\left(\frac{1-R}{2}\right)^{\alpha}
$$

where $\sigma_{D}$ is the median fatigue strength at $5 \times 10^{6}$ cycles, $R$ is the loading ratio, $A=1.43$ for surface flaws, $H V$ is the material hardness, $\sqrt{\text { area }}$ is the square root of the projected area of a flaw on the plane experiencing the maximum normal stress, and $\alpha$ is a mean stress sensitivity factor defined by Eq (2)

$$
\alpha=0.226+\mathrm{HV} \times 10^{-4}
$$

FIG. 12

Kitagawa diagram of punched and polished specimens.

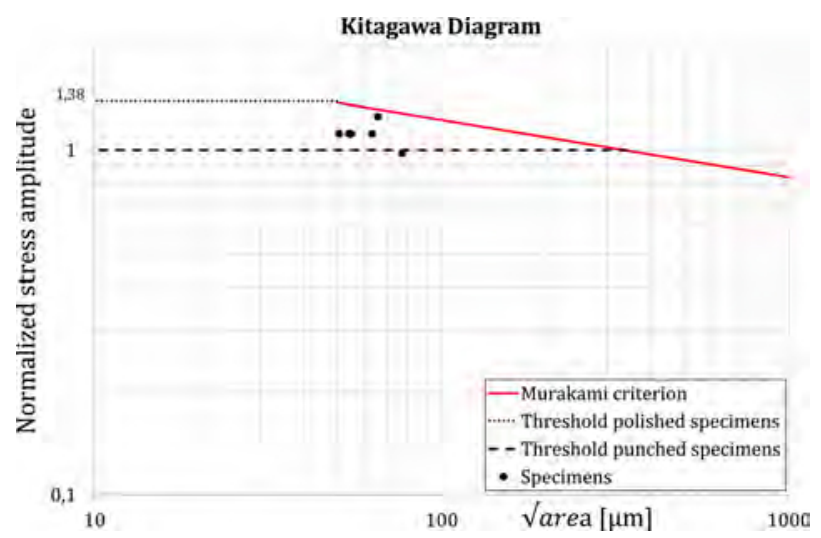


FIG. 13

Finite element model used for simulation with ideal defect geometry.

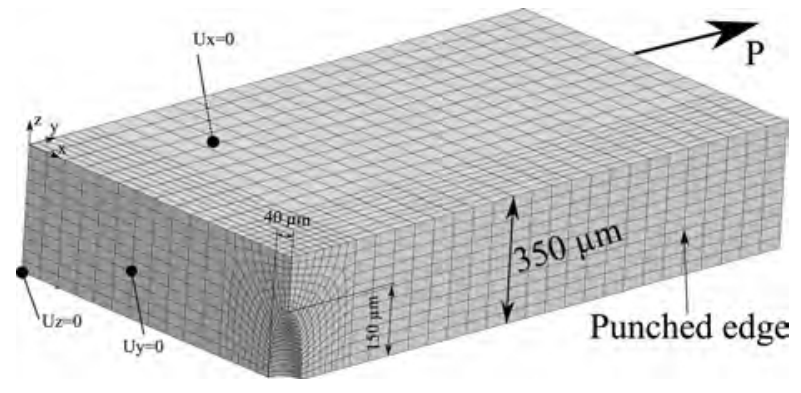

The Kitagawa diagram is presented in Fig. 12. Murakami criterion predicts that defects with a flaw size lower than $50 \mu \mathrm{m}$ should not affect the fatigue strength, but the fatigue strength drop observed for punched specimens with typical flaw sizes ranging from 50 to $80 \mu \mathrm{m}$ questions this assumption. This can be explained by the fact that the material around the defect is also altered by the punching process. Murakami criterion was elaborated for small defects compared to the component dimensions and without any effect of the process. In our case, the sheet thickness and the flaw size are comparable. Moreover, punching process induces a material property gradient, which is due to local hardening, and a stress gradient, which is strongly influenced by the residual stress field. Given these effects, Murakami criterion does not provide correct assessment of the fatigue limit in this case. Furthermore, since flaw sizes are close to the transition of the criterion, linear elastic fracture mechanics might not be suitable here, and elastic-plastic fracture mechanics should be applied instead.

\section{Finite Element Analysis and Defects}

Since the Murakami parameter, $\sqrt{\text { area }}$, does not provide correct results, a local high cycle fatigue strength criterion has been evaluated to try accounting for the local

FIG. 14

Crossland fatigue criterion for Fe-Si steel sheets applied with FEA results computed with local stress using elastic and elastic-plastic constitutive models.

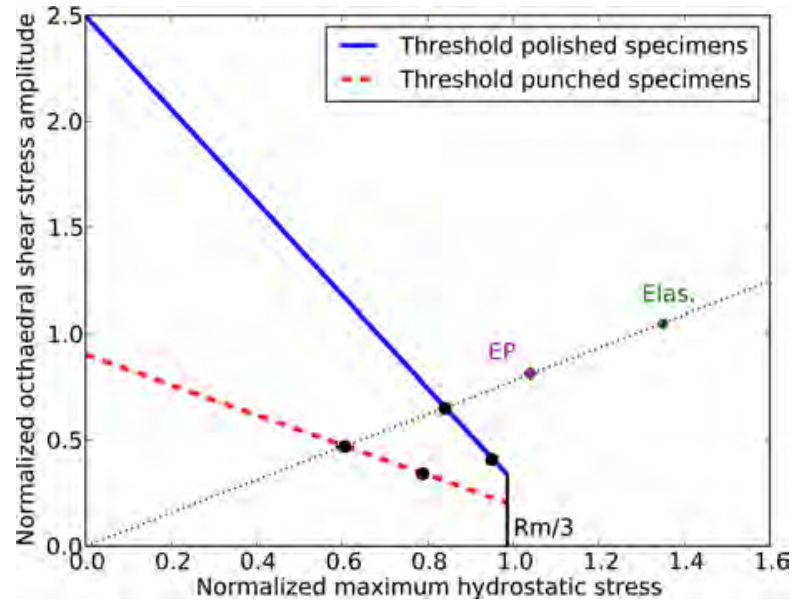


stress state around defects. The Crossland criterion has been chosen because it gives good results under proportional loadings. Finite element analyses have been performed on idealized defects as illustrated in Fig. 13. The material is supposed to be homogeneous and isotropic with linear elastic and elastic-plastic constitutive models. The boundary conditions are presented in Fig. 13. The applied load direction is taken parallel to the $Y$-axis. The idealized defect geometry is $40 \mu \mathrm{m}$ deep and $150 \mu \mathrm{m}$ long, which is about the half of the sheet thickness. The mesh is obtained using parallelipipedic elements with quadratic displacement interpolation and it is refined around the defect.

The theoretical stress concentration factor $(\mathrm{Kt})$ due to the defect is calculated as $K_{t}=\sigma_{y y}^{\max } / \sigma_{\text {net }}$, where $\sigma_{y y}^{\max }$ is the maximum stress in the loading direction and $\sigma_{\text {net }}$ is the normal stress on the $Y=0$ cross-section. Its value is around 2.5.

According to the obtained results, Crossland local approach [14] with both elastic and elastic-plastic material behavior does not lead to safe fatigue strength assessment in the case of material with punching defects (Fig. 14). For further analyses, a non-local high cycle fatigue strength criterion will be evaluated to consider the stress strain gradient effect $[15,16]$. Also, real defect geometries together with elastic-plastic calculations will be used to better estimate the local stress and strain fields.

\section{Conclusion and Prospects}

In this paper, the high cycle fatigue strength of specimens punched out in electrical thin steel sheets was investigated. It was shown that there is a significant decrease in the fatigue strength for punched specimens compared to specimens with polished edges. This can be primarily explained by the geometrical defects induced on the edges by the punching operation. Indeed, SEM observations show that cracks always initiate on punching defects. Four types of defects were identified: (i) vertical stripes from top to bottom of the edge, (ii) depressions in the top surface, (iii) defects in the sheared zone, and (iv) defects in the fracture zone. Results of SEM observations and three dimensional surface topography shows that initiation always occurs on a defect localized in the fracture zone. No effect of the temperature on the median fatigue strength at $5 \times 10^{6}$ cycles was observed. However, a small influence of temperature is visible for high stress levels where crack initiation is governed by macroscopic plasticity. According to the Murakami parameter $\sqrt{\text { area }}$, geometrical defects do not solely explain the fatigue strength drop for punched specimens. Indeed, fatigue crack initiation is also promoted by the large tension residual stresses and probably the hardening induced on the edge by the punching operation. Micro-hardness and XRD measurements near cut edges exhibit the same $200 \mu \mathrm{m}$ depth for the mechanically affected zone.

Improving the fatigue strength of punched parts requires a better understanding of the punching operation, and its effect on edge surfaces, residual stresses and hardening. Safely designing electric motor parts against high cycle fatigue failure requires an adapted fatigue criterion. Since Murakami and Crossland criteria do not provide a reliable estimation of the fatigue strength, non-local HCF criteria will be investigated using elastic-plastic simulations on idealized and real 
defects. Since the mean grain size is close to the defect size, which is about half the thickness, the effect of the microstructure cannot be neglected and polycrystalline plasticity is a promising way to better predict fatigue crack initiation in that case.

\section{References}

[1] Lara, A., Picas, I., and Casellas, D., "Effect of the Cutting Process on the Fatigue Behaviour of Press Hardened and High Strength Dual Phase Steels," J. Mat. Process. Technol., Vol. 213, No. 11, 2013, pp. 1908-1919.

[2] Sanchez, L., Gutiérrez-Solana, F., and Pesquera, D., "Fatigue Behaviour of Punched Structural Plates," Eng. Fail. Anal., Vol. 11, No. 5, 2004, pp. 751-764.

[3] Böhling, M., Bauch, J., and Ullrich, H.-J., "Effect of the Cutting Technique on the Residual Stress Distribution of Cut Edges in FeSi3 Transformer Sheets," Cryst. Res. Technol., Vol. 44, No. 11, 2009, pp. 1185-1191.

[4] Dehmani, H., Brugger, C., Palin-Luc, T., Mareau, C., and Koechlin, S., "Experimental Study of the Impact of Punching Operations on the High Cycle Fatigue Strength of Fe-Si Thin Sheets," Int. J. Fatigue, Vol. 82, Part 3, 2016, pp. 721-729.

[5] Bode, B., Brueckner-Foit, A., and Zeismann, F., "Quasi-Static and Cyclic Failure Behavior of Electric Sheet Material," Int. J. Fatigue, Vol. 82, Part 2, 2016, pp. 350-360.

[6] Achouri, M., Gildemyn, E., Germain, G., Dal Santo, P., and Potiron, A., "Influence of the Edge Rounding Process on the Behaviour of Blanked Parts: Numerical Predictions With Experimental Correlation," Int. J. Adv. Manuf. Technol., Vol. 71, Nos. 5-8, 2014, pp. 1019-1032.

[7] Hubert, O., "Influence des Contraintes Internes et de la Structure des Dislocations sur les Couplages Magnétomécaniques dans les Alliages Fe$3 \%$ Si à Grains non Orientés [Influence of Internal Stress and Dislocation Structures on Magneto Mechanical Couplings in Non Oriented Grain Fe3\%Si Alloys]," Ph.D. thesis, Université de Technologie de Compiègne, France, 1998.

[8] Maurel, V. and Ossart, F., "Residual Stresses in Punched Laminations: Phenomenological Analysis," J. Appl. Phys., Vol. 93, No. 10, 2003, p. 7106.

[9] ISO 10113:2006, "Metallic Materials-Sheet and Strip-Determination of Plastic Strain Ratio," International Organization for Standardization, Geneva, Switzerland, 2006.

[10] Itoga, H., Tokaji, K., Nakajima, M., and Ko, H.-N., "Effect of Surface Roughness on Step-Wise S-N Characteristics in High Strength Steel," Int. J. Fatigue, Vol. 25, No. 5, 2003, pp. 379-385.

[11] Stromeyer, C. E., "The Determination of Fatigue Limits Under Alternating Stress Conditions," Proc. R. Soc. London A, Vol. 90, No. 620, 1914, pp. 411-425.

[12] Schayes, C., Vogt, J.-B., Bouquerel, J., Palleschi, F., and Zaefferer, S., "Cyclic Plasticity Mechanism of the M330-35A Steel," Int. J. Fatigue, Vol. 82, Part 3, 2016, pp. 530-539. 
[13] Murakami, Y., Metal Fatigue: Effect of Small Defects and Non-Metallic Inclusions, Elsevier, Amsterdam, Switzerland, 2002.

[14] Crossland, B., "Effect of a Large Hydrostatic Pressure on the Torsional Fatigue Strength of an Alloy Steel," in International Conference on Fatigue of Metals, Institute of Mechanical Engineering, London, 1959, pp. 138-149.

[15] Gadouini, H., Nadot, Y., and Rebours, C., "Influence of Mean Stress on the Multiaxial Fatigue Behaviour of Defective Materials," Int. J. Fatigue, Vol. 30, No. 9, 2008, pp. 1623-1633.

[16] El May, M., Saintier, N., Palin-Luc, T., and Devos, O., "Non-Local High Cycle Fatigue Criterion for Metallic Materials With Corrosion Defects," Fatigue Fract. Eng. Mater. Struct., Vol. 38, No. 9, 2015, pp. 1017-1025. 